\title{
Bidirectional progressive optimization of carbon and nitrogen defects in solar-driven regenerable adsorbent to remove $U V$-filters from water
}

Chao Zhu ${ }^{1}$, Yi Shen ${ }^{1 *}$, Shaobin Wang ${ }^{2}$, Shuang Song ${ }^{1}$, Qile Fang 3 , Da Wang ${ }^{1}$, Haomiao $\mathrm{Xu}^{4}$, Renlan $\mathrm{Liu}^{5}$, Zhiqiao $\mathrm{He}^{1}$.

1. Key Laboratory of Microbial Technology for Industrial Pollution Control of Zhejiang Province, College of Environment, Zhejiang University of Technology, Hangzhou 310032, P. R. China.

2. School of Chemical Engineering and Advanced Materials, The University of Adelaide, Adelaide, SA 5005, Australia.

3. Research and Development Center for Watershed Environmental Eco-Engineering, Beijing Normal University, Zhuhai 519087, P. R. China

4. School of Environmental Science and Engineering, Shanghai Jiao Tong University, 800 Dongchuan Road, Minhang District, Shanghai 200240, P. R. China.

5. College of Life and Environmental Science, Wenzhou University, Wenzhou 325035, P. R. China.

*Corresponding Author: Yi Shen

E-mail: shenyi@zjut.edu.cn 
Synthesis of 3D DOAs. GO dispersions were purchased from J\&K, Shanghai, China. CTF nanosheets were synthesized as follows: 1,4-dicyanobenzene (4 mmol) of was dissolved in $\mathrm{CF}_{3} \mathrm{SO}_{3} \mathrm{H}(2.5 \mathrm{~mL})$ under nitrogen atmosphere at $0{ }^{\circ} \mathrm{C}$. The resulting viscous solution was stirred for $1.5 \mathrm{~h}$ before heating at $100{ }^{\circ} \mathrm{C}$ for $20 \mathrm{~min}$. The obtained transparent solid samples were ground into a powder using an agate mortar, washed three times with water and ethanol, and dried at $80^{\circ} \mathrm{C}$ in an oven overnight for further synthesis.

In preparation of $3 \mathrm{D}$ DOAs, the procedure was described below. The GO nanosheets dispersion $(2.5 \mathrm{mg} / \mathrm{mL}, 10 \mathrm{~mL})$ was placed in $25 \mathrm{~mL}$ beakers. CTF nanosheets $(25 \mathrm{mg})$ were mixed into the $\mathrm{GO}$ solution and stirred to form a homogenous dispersion. Subsequently, the dispersions $(1 \mathrm{~mL})$ were poured into cylindrical molds $(1.8 \mathrm{~mL})$ followed by freeze-drying for $1 \mathrm{~d}$, to obtain 3D DOA-0. Synthesis of 3D DOA-1, and 3D DOA-2 was conducted by chemical reduction of 3D DOA-0. In a typical process, 3D DOAs were chemically reduced by sodium borohydride vapor at $90{ }^{\circ} \mathrm{C}$ for $24 \mathrm{~h}$, followed by vacuum-drying at $60{ }^{\circ} \mathrm{C}$ for $24 \mathrm{~h}$ to produce 3D DOA-1. Similarly, 3D DOA-2 was obtained by using a strong reducing reagent, hydrazine hydrate vapor for synthesis.

Characterizations of the 3D DOAs. Elemental $(\mathrm{C}, \mathrm{H}, \mathrm{N})$ analyses were conducted using an EA112 CHN elemental analyzer (Thermo Finnigan). X-ray photoelectron spectroscopy (XPS) experiments were performed on a Thermo Scientific ESCA-Lab-200i-XL spectrometer (Waltham, MA) using monochromatic Al Al $\alpha$ radiation $(1486.6 \mathrm{eV})$ and the $\mathrm{C} 1 \mathrm{~s}$ and $\mathrm{N} 1 \mathrm{~s}$ peaks in the spectra were analyzed using XPS Peak 4.1 software. Raman spectra were recorded using a Lab Ram HRUV Raman spectrometer (JDbin-yvon, FR). Laser excitation was provided by an $\mathrm{Ar}^{+}$laser at a wavelength of $532 \mathrm{~nm}$. Fourier transform infrared (FTIR) spectroscopy was recorded in the $4000-400 \mathrm{~cm}^{-1}$ wavenumber region with a resolution of $4 \mathrm{~cm}^{-1}$ using a Nicolet Thermo NEXUS 670 spectrometer. X-ray diffraction (XRD) patterns were 
recorded with a PANalytical X'Pert PRO powder diffractometer using $\mathrm{Cu} \mathrm{K} \alpha$ radiation $(\lambda=0.1541 \mathrm{~nm})$. The working voltage was $40 \mathrm{kV}$ and the working current was $40 \mathrm{~mA}$. The patterns were collected with a $2 \theta$ range from $10^{\circ}$ to $80^{\circ}$ at a step of 0.0167 . Scanning electron microscopy (SEM) was performed on a Nano nova 450 SEM (FEI, Netherlands). The Brunauer-Emmett-Teller (BET) surface area was estimated using nitrogen adsorption-desorption isotherm at $-196{ }^{\circ} \mathrm{C}$ on a NOVA-2000E surface area analyzer.

UV-vis diffuse reflection spectra (DRS) of 3D DOAs and CTF powders were carried out on a Shimadzu UV-2550 UV-vis spectrophotometer in the wavelength range of $200-800 \mathrm{~nm}$ using $\mathrm{BaSO}_{4}$ as a reference for baseline correction. Furthermore, with the help of the Kubelka-Munk function, the reflectance data were converted into their absorbance terms. The periodic on/off photocurrent responses, electrochemical impedance spectra (EIS) and Mott-Schottky plots were recorded using a three-electrode quartz cell on a $\mathrm{CHI} 660 \mathrm{E}$ electrochemical workstation $(\mathrm{CH}$ Instrument, USA). For the periodic on/off photocurrent responses, the samples were dispersed on indium tin oxide (ITO) glass and used as the working electrode, and a Pt flake and $\mathrm{Ag} / \mathrm{AgCl}$ (saturated $\mathrm{KCl}$ ) were used as the counter and reference electrode, respectively. The electrolyte was $0.1 \mathrm{M} \mathrm{Na}_{2} \mathrm{SO}_{4}$ solution and the light source was a $250 \mathrm{~W}$ xenon high-brightness cold light source (XD-300) equipped with a UV cut-off filter $(\lambda>400 \mathrm{~nm})$. The EIS were recorded using an alternating current (ac) voltage magnitude of $5 \mathrm{mV}$ over a frequency range of $10^{6}-10^{-2} \mathrm{~Hz}$ in dark. The Mott-Schottky plot was performed in $0.1 \mathrm{~mol} / \mathrm{L}^{-1} \mathrm{Na}_{2} \mathrm{SO}_{4}(\mathrm{pH}=6.8)$ at a frequency of $1000 \mathrm{~Hz}$. The samples were dispersed on fluorine-doped tin oxide (FTO) glass and used as the working electrode. The voltage was scanned from the open-circuit $(0.2 \mathrm{~V})$ to $1.0 \mathrm{~V}$. The position of conduction band was approximately equal to the flat band. The conduction band was obtained from the Mott-Schottky analysis by extrapolation of the Mott-Schottky plot to intersect with the x-axis. The active radicals were examined using a Bruker electron spin resonance (ESR) spectrometer employing 
5,5-dimethyl-1-pyrroline N-oxide (DMPO) as a spin trapping reagent. Typically, 3D DOAs $(30 \mathrm{mg}$ ) was added to an $80 \mathrm{mM}$ DMPO solution with an aqueous dispersion for DMPO- $\cdot \mathrm{OH}$ and methanol dispersion for $\mathrm{DMPO}-\mathrm{O}_{2}{ }^{-}$with irradiation under the Xenon lamp equipped with an AM1.5, $100 \mathrm{~mW} / \mathrm{cm}^{2}$ filter.

Adsorption experiments. Benzophenone (BP, 99.5\%+, Aladdin Co. Ltd.), 4-hydroxybenzophenone (4-HBP, 99.5\%+, Aladdin Co. Ltd.) and 2,2',4,4'-tetrehydroxybenzophenone (BP-2, 99\%+, J\&K Chemical) were selected as model pollutants. Batch adsorption experiments were carried out in PTFE screw cap vials $(60 \mathrm{~mL})$ sealed with tin foil at $25 \pm 1^{\circ} \mathrm{C}$. The samples of 3D DOA-0, 3D DOA-1, and 3D DOA-2 were used as an adsorbent in the liquid phase, and the samples were prepared into a background solution containing $0.01 \mathrm{~mol} / \mathrm{L} \mathrm{CaCl}_{2}$ in deionized water using $200 \mathrm{mg} / \mathrm{L} \mathrm{NaN}_{3}$ as a bio-inhibitor followed by ultrasonication to stabilize the dispersed solution. All the tests were conducted in duplicate.

Adsorption kinetic studies were conducted using an initial BP, 4-HBP or BP-2 concentration of $20 \mu \mathrm{mol} / \mathrm{L}$. The solid-to-water ratio for the tests were $1 \mathrm{mg}$ per 50 $\mathrm{mL}$. The remaining concentrations of BP, 4-HBP or BP-2 were measured from $10 \mathrm{~s}$ to $1800 \mathrm{~s}$. Isotherm experiments were performed using a solid-to-water ratio of 3D DOAs (1 mg) and $50 \mathrm{~mL}$ of BP, 4-HBP or BP-2 solution. The initial concentrations of the solutions were controlled to obtain an equilibrium concentration in the range of 5-200 $\mu \mathrm{mol} / \mathrm{L}$ for all three pollutants. The vials were placed on a shaker and agitated in dark at $120 \mathrm{rpm}$ for $4 \mathrm{~h}$. The solution was separated from the solid by filtration using a $0.22 \mu \mathrm{m}$ membrane filter.

Kinetic models. The pseudo first-order model can be presented as follows:

$$
\ln \left(q_{\mathrm{e}}-q_{\mathrm{t}}\right)=\ln q_{\mathrm{e}}-k_{1} t
$$

where $k_{1}$ is the rate constant of the pseudo first-order model for adsorption $(1 / \mathrm{h}) ; q_{\mathrm{e}}$ and $q_{\mathrm{t}}$ are the amount of adsorbed pollutants at equilibrium and at time $\mathrm{t}(\mathrm{mg} / \mathrm{g})$, 
respectively. The $k_{1}$ and $q_{\mathrm{e}}$ values can be determined from the slope and intercept of the linear fitting of $\ln \left(q_{\mathrm{e}}-q_{\mathrm{t}}\right)$ versus $t$.

The pseudo second-order model is given by:

$$
\mathrm{t} / q_{\mathrm{t}}=1 / k_{2} q_{\mathrm{e}}^{2}+t / q_{\mathrm{e}}
$$

where $k_{2}$ is the rate constant of the pseudo second-order model for adsorption (g/(mg $\cdot \mathrm{h})$ ), while $q_{\mathrm{e}}$ and $q_{\mathrm{t}}$ are the same parameters defined in the pseudo first-order model. The $k_{2}$ and $q_{\mathrm{e}}$ values can be determined from the slope and intercept of the linear fitting of $t / q_{\mathrm{t}}$ versus $t$.

Adsorption isotherm models. The Langmuir and Freundlich models were utilized to fit the adsorption isotherms.

The following expression describes the Langmuir equation:

$$
q_{\mathrm{e}}=q_{\mathrm{m}} C_{\mathrm{e}} /\left(K_{\mathrm{L}}+C_{\mathrm{e}}\right)
$$

where $q_{\mathrm{e}}(\mathrm{mg} / \mathrm{g})$ is the equilibrium-sorbed concentration, $C_{\mathrm{e}}(\mathrm{mg} / \mathrm{L})$ is the equilibrium solution-phase concentration, $K_{\mathrm{L}}(\mathrm{L} / \mathrm{g})$ is the Langmuir constant and $q_{\mathrm{m}}(\mathrm{mg} / \mathrm{g})$ represents the maximum adsorption capacity of the adsorbent.

The following expression describes the Freundlich equation:

$$
q_{\mathrm{e}}=K_{\mathrm{f}} C_{\mathrm{e}}{ }^{N}
$$

where $K_{\mathrm{f}}[(\mathrm{mg} / \mathrm{g}) /(\mathrm{mg} / \mathrm{L}) \mathrm{N}]$ is the Freundlich affinity coefficient and $N$ is the exponential coefficient.

Percentage of the regenerated aerogels. The percentage of the adsorption capacity of the aerogels regenerated can be presented as follows: 


$$
R=q_{\mathrm{n}+1} / q_{\mathrm{n}}
$$

where $R$ is the percentage of the adsorption capacity regenerated, $q_{\mathrm{n}}$ is adsorption capacity in cycle $n$. 


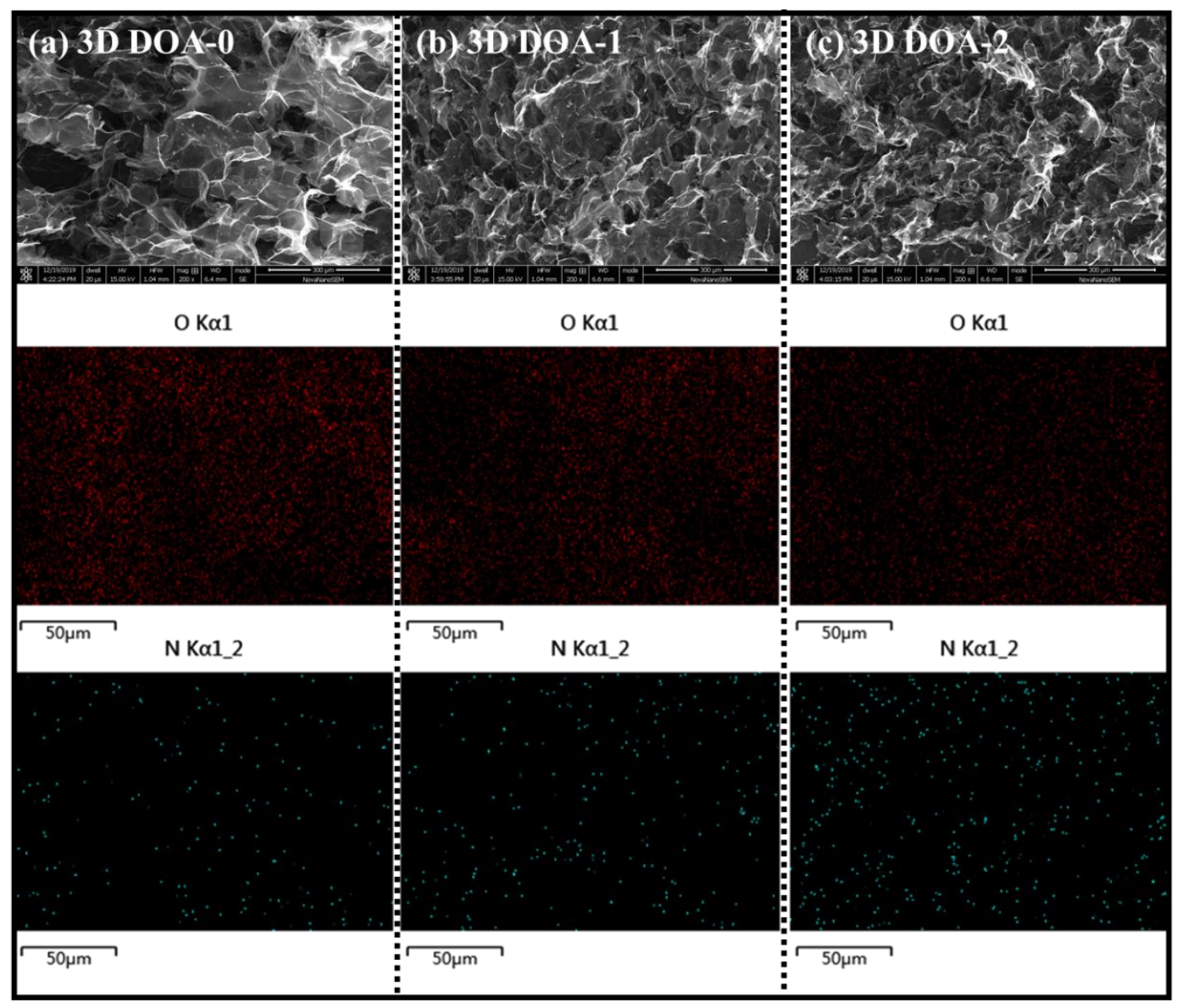

Figure S-1. SEM images of the 3D DOAs on a $300 \mu \mathrm{m}$ scale and mapping images on a $50 \mu \mathrm{m}$ scale: (a) 3D DOA-0, (b) 3D DOA-1 and (c) 3D DOA-2. 


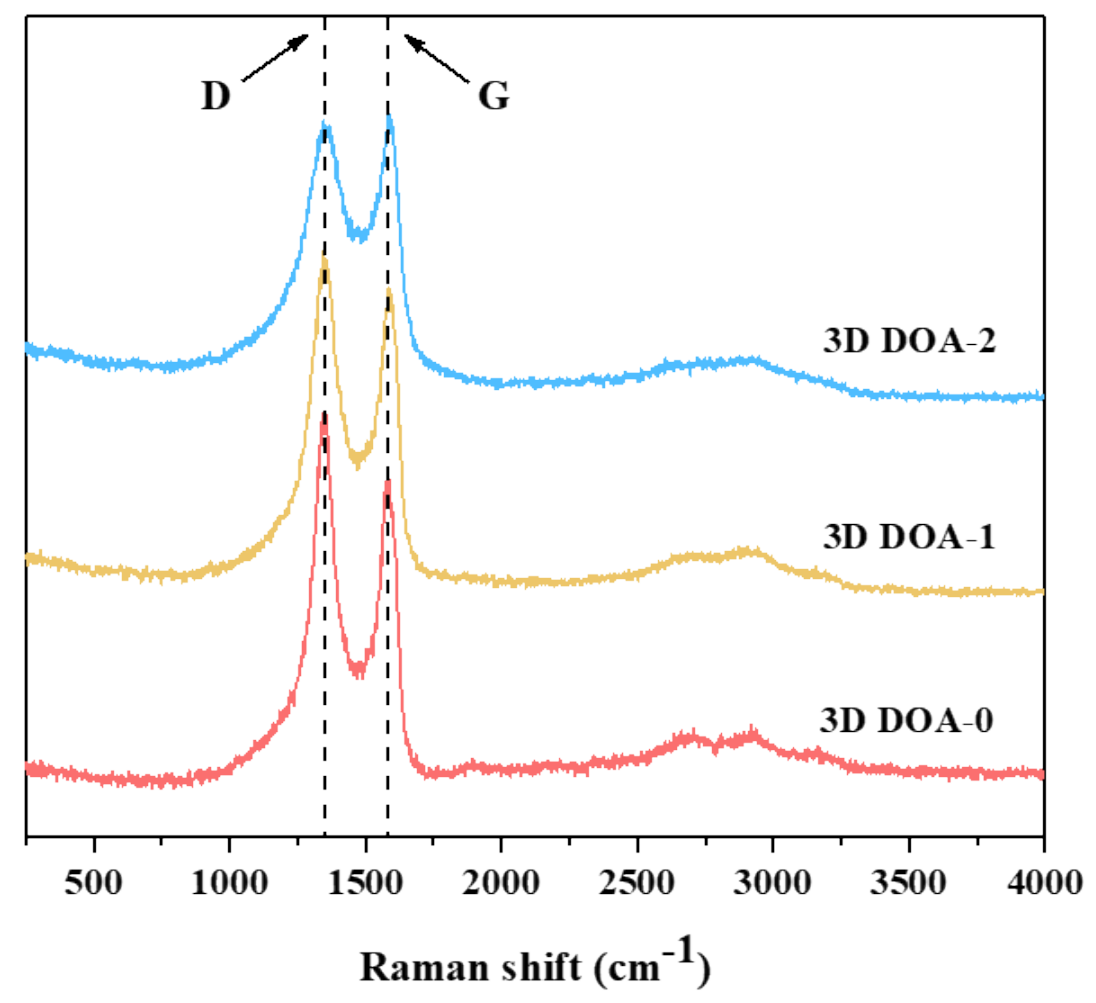

Figure S-2. Raman spectra of 3D DOA-0, 3D DOA-1 and 3D DOA-2. 

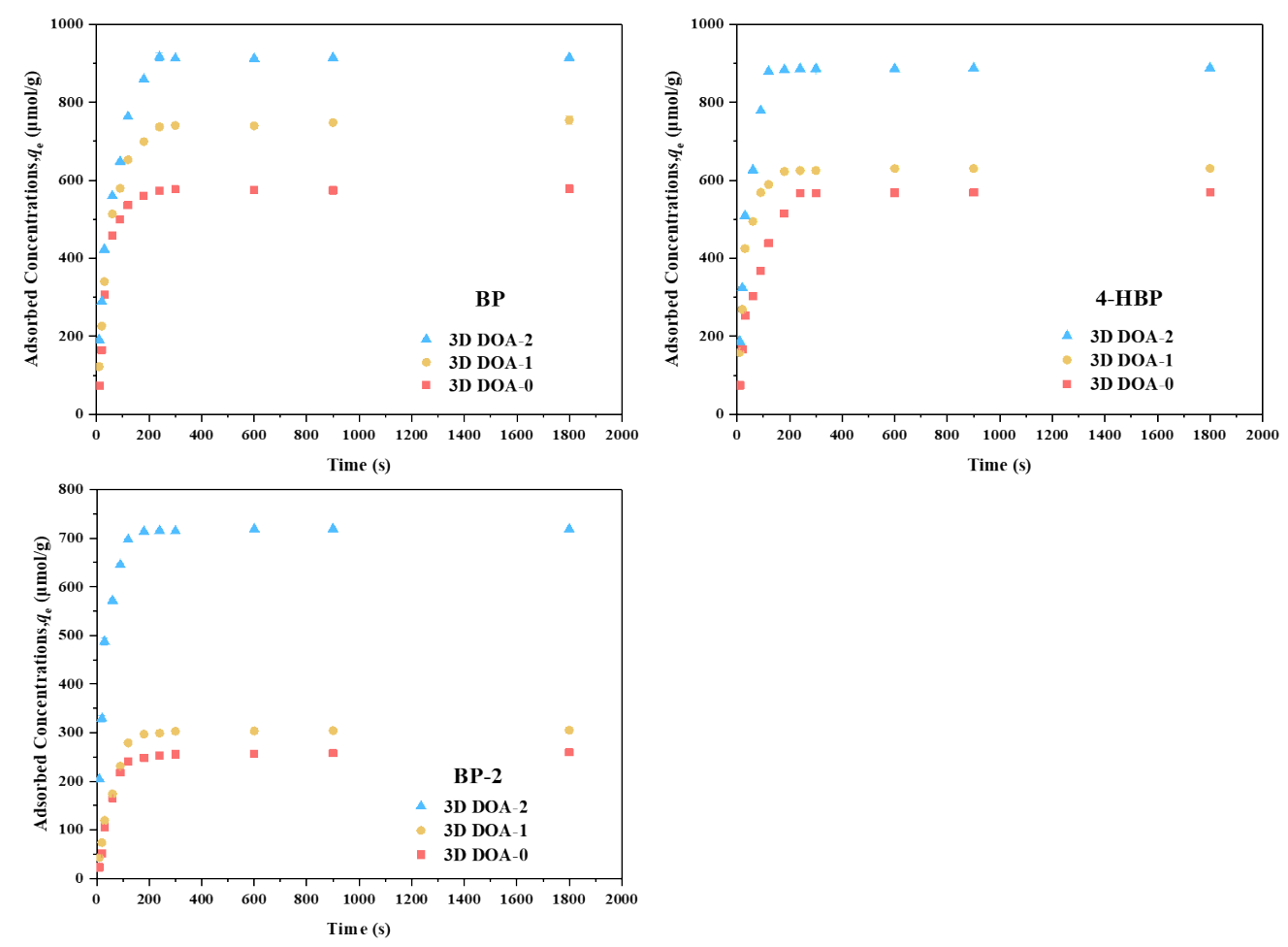

Time (s)

Figure S-3. Adsorption kinetics of BP, 4-HBP and BP-2 on 3D DOA-0, 3D DOA-1 and 3D DOA-2. 

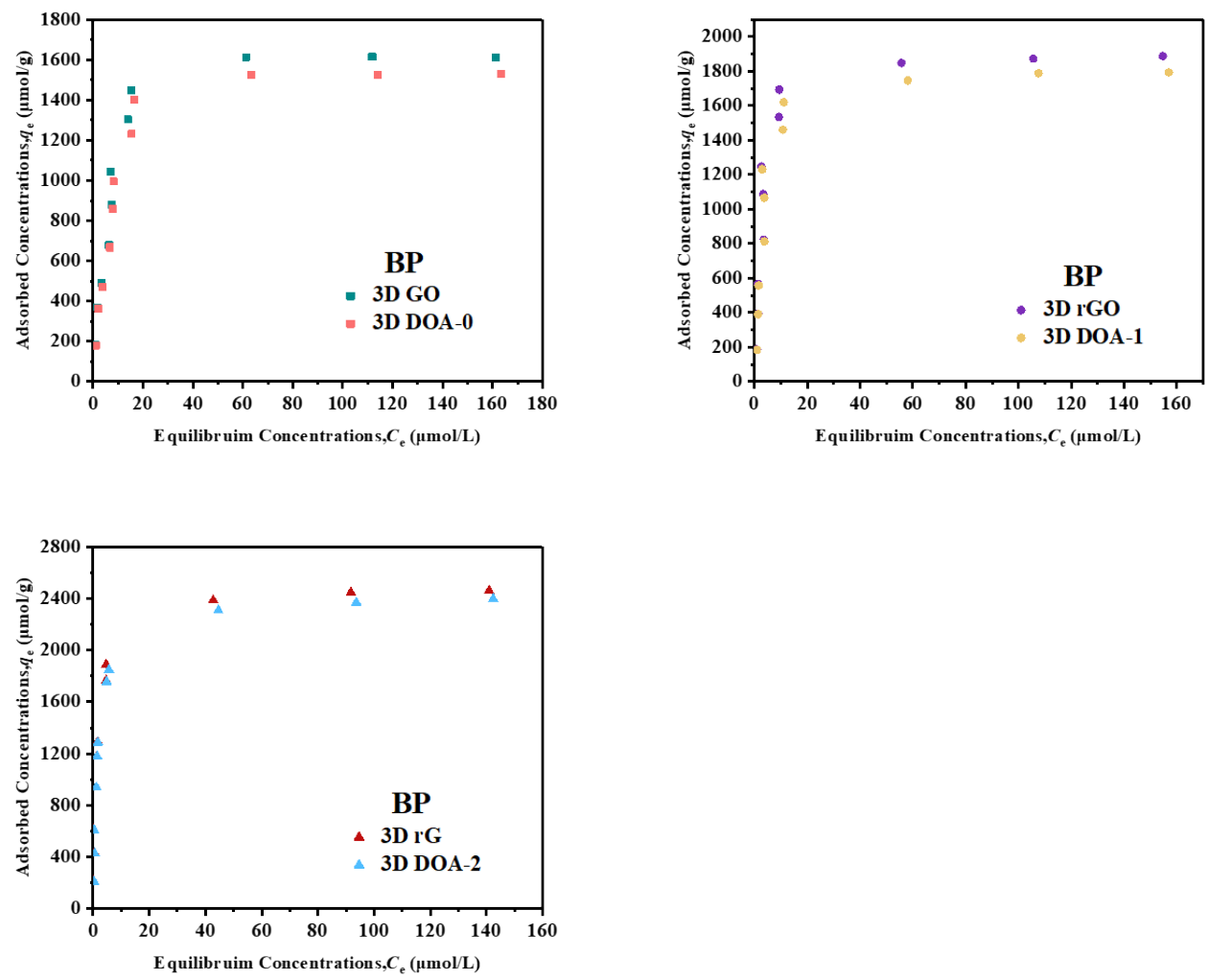

Figure S-4. Comparison of adsorption capacity between 3D DOAs and 3D GOs. 


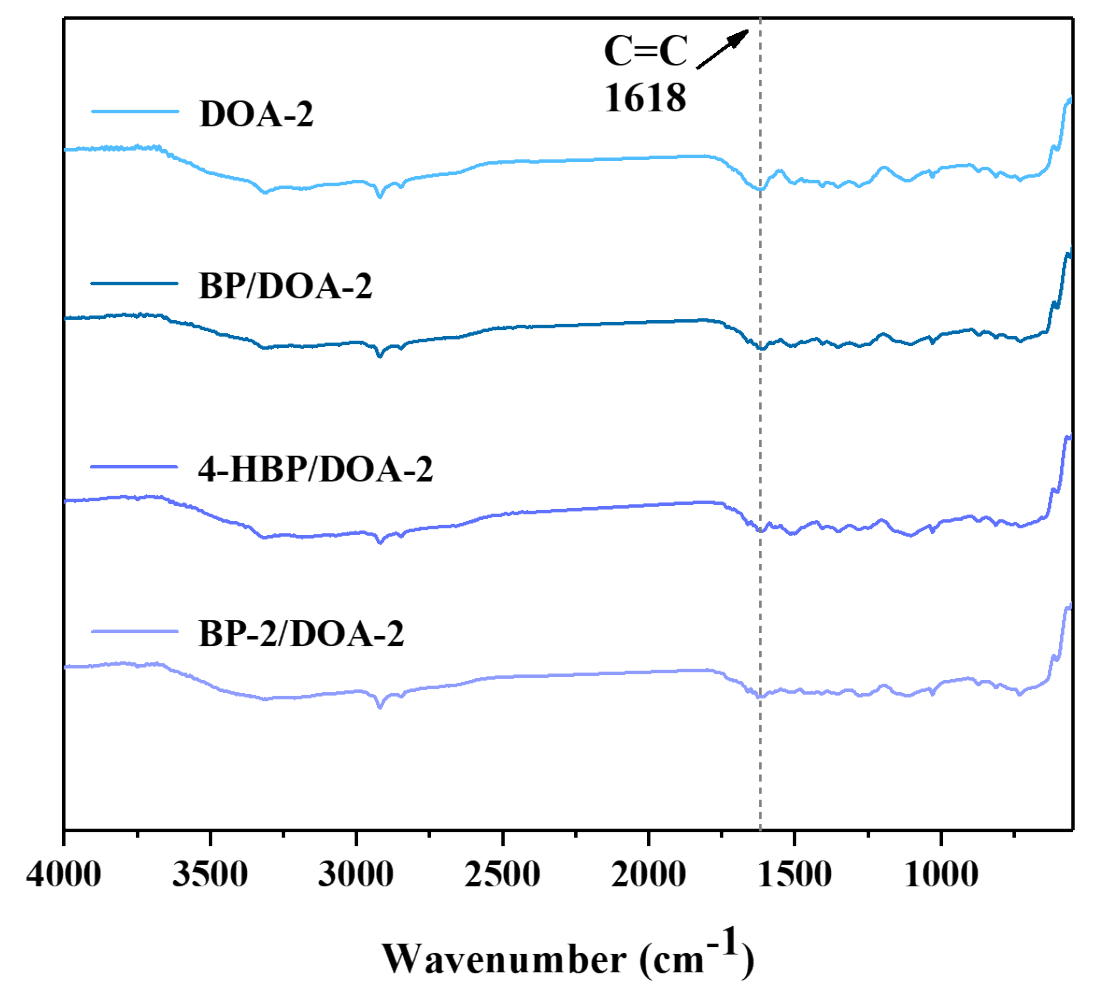

Figure S-5. FTIR spectra of 3D DOA-2 before and after the adsorption of BP, 4-HBP and BP-2. 

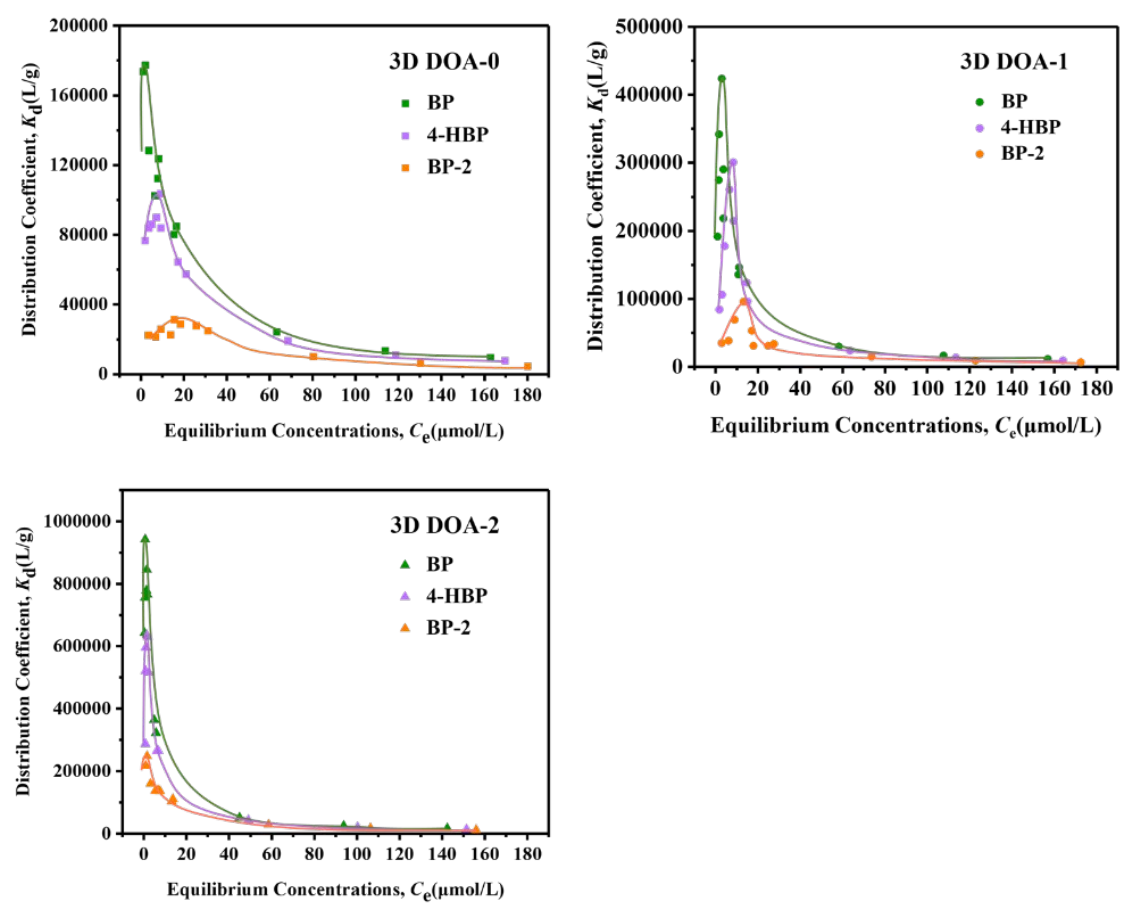

Figure S-6. The variations in the distribution coefficient $\left(K_{\mathrm{d}}\right)$ with the equilibrium concentration for the adsorption of BP, 4-HBP and BP-2 onto 3D DOA-0, 3D DOA-1 and 3D DOA-2. 


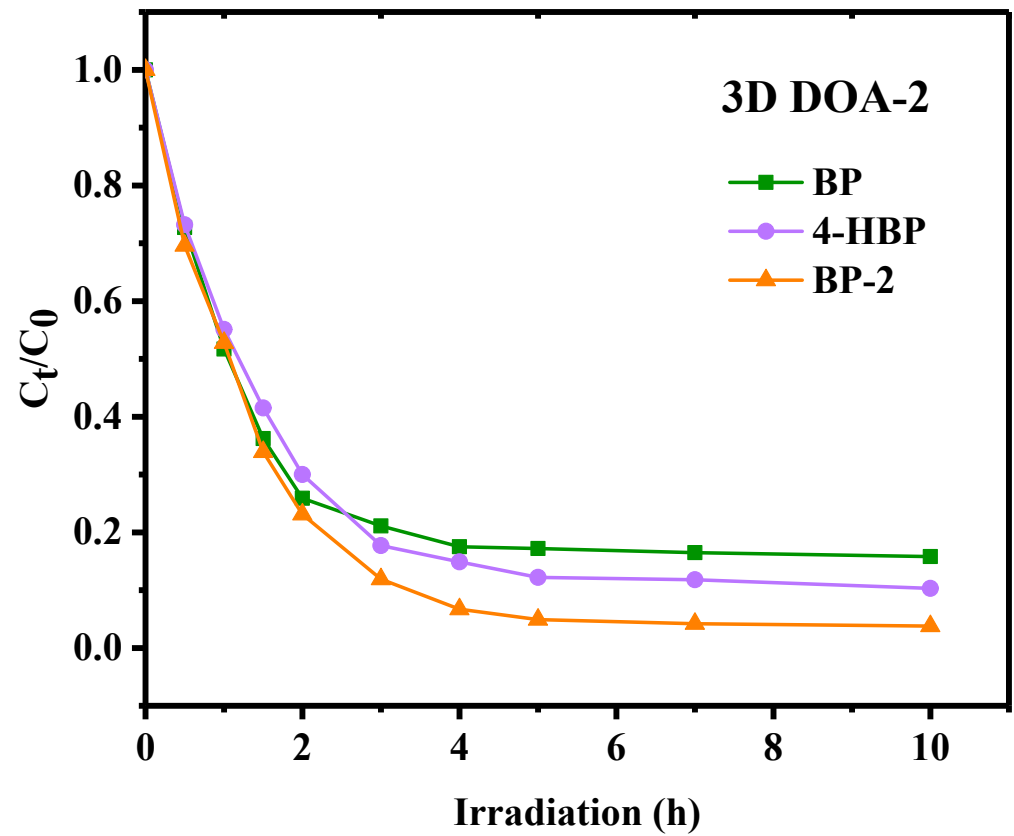

Figure S-7. Photocatalytic degradation of UV-filters over 3D DOA-2. 


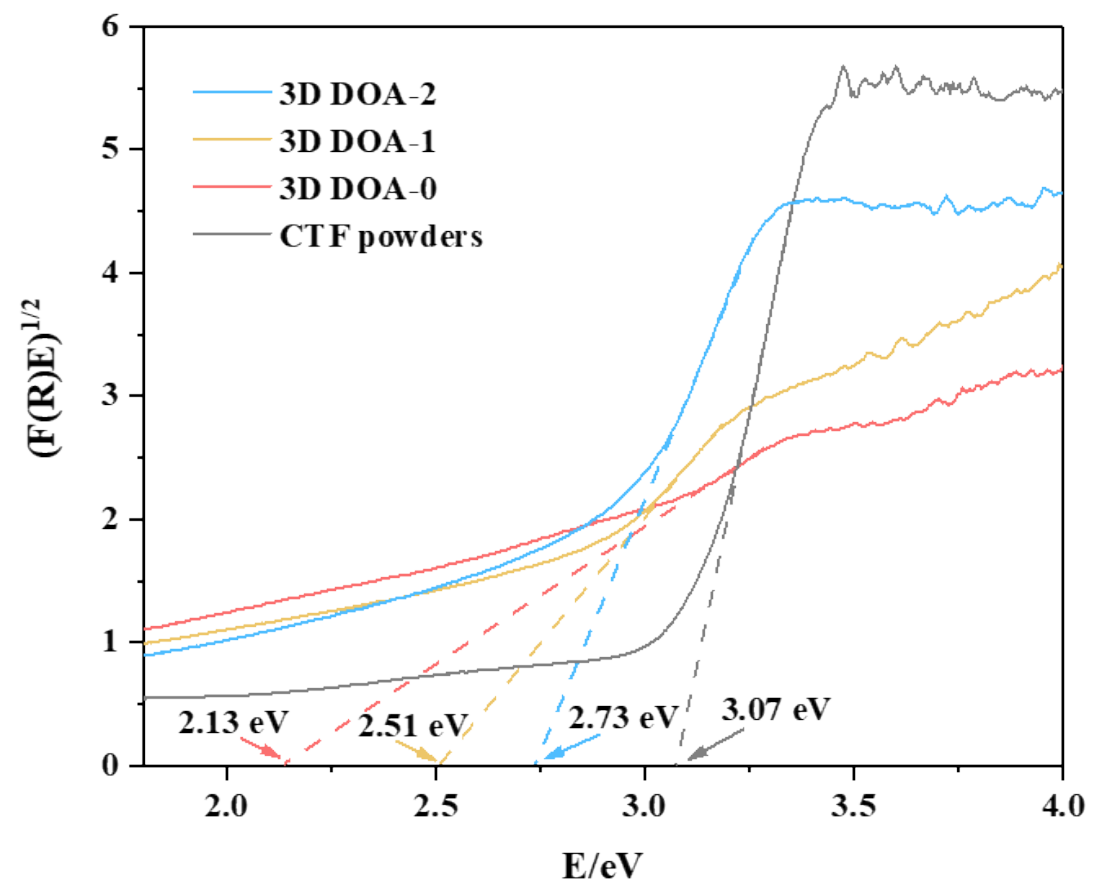

Figure S-8. Kubelka-Munk plots obtained for 3D DOA-0, 3D DOA-1, 3D DOA-2 and CTF powders. 


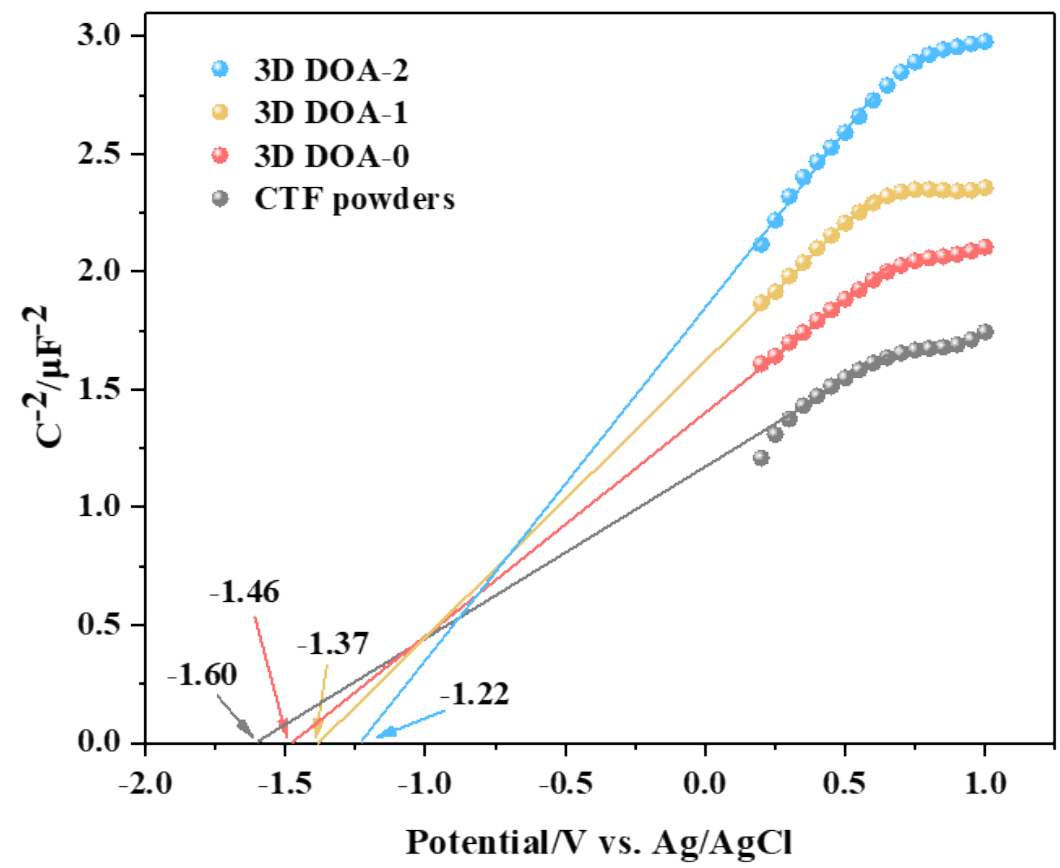

Figure S-9. The typical Mott-Schottky plots (scatter) and simulated plots (lines) for 3D DOA-0, 3D DOA-1, 3D DOA-2 and CTF powders. 


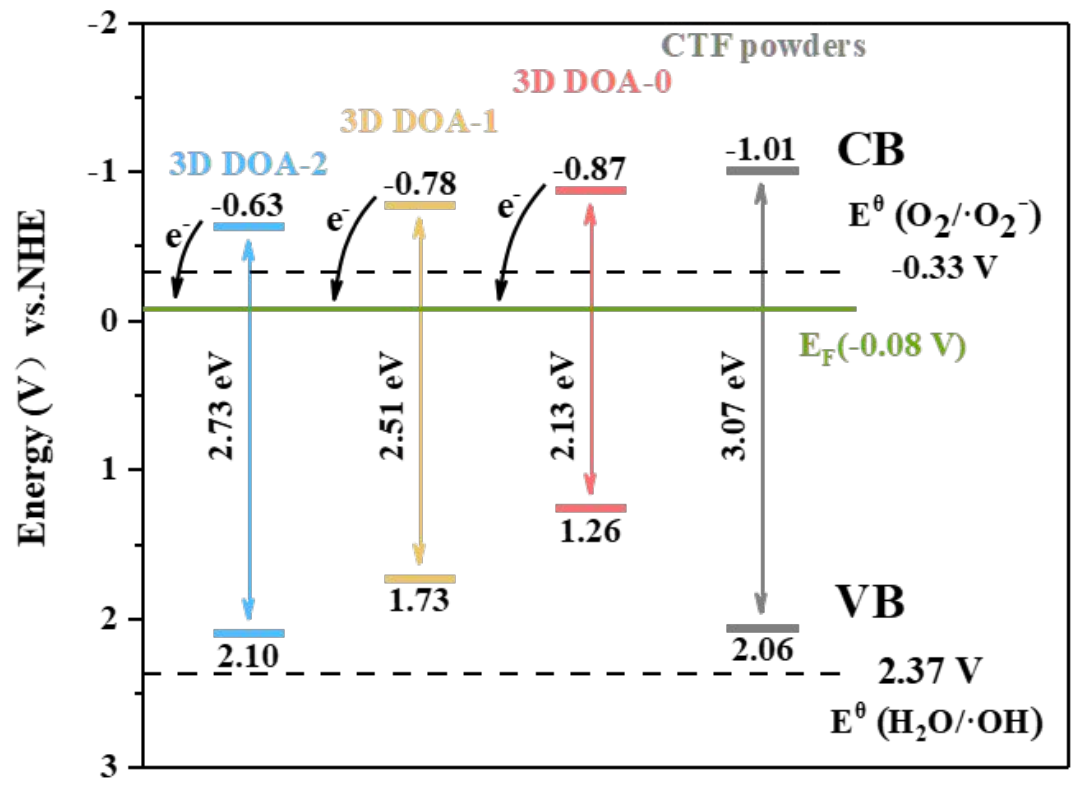

Figure S-10. The energy band structure of the 3D DOAs and CTF powders ( $E_{\mathrm{CB}}$ vs. NHE was calculated from $E_{\mathrm{CB}} \mathrm{Vs} . \mathrm{Ag} / \mathrm{AgCl}$ ). 


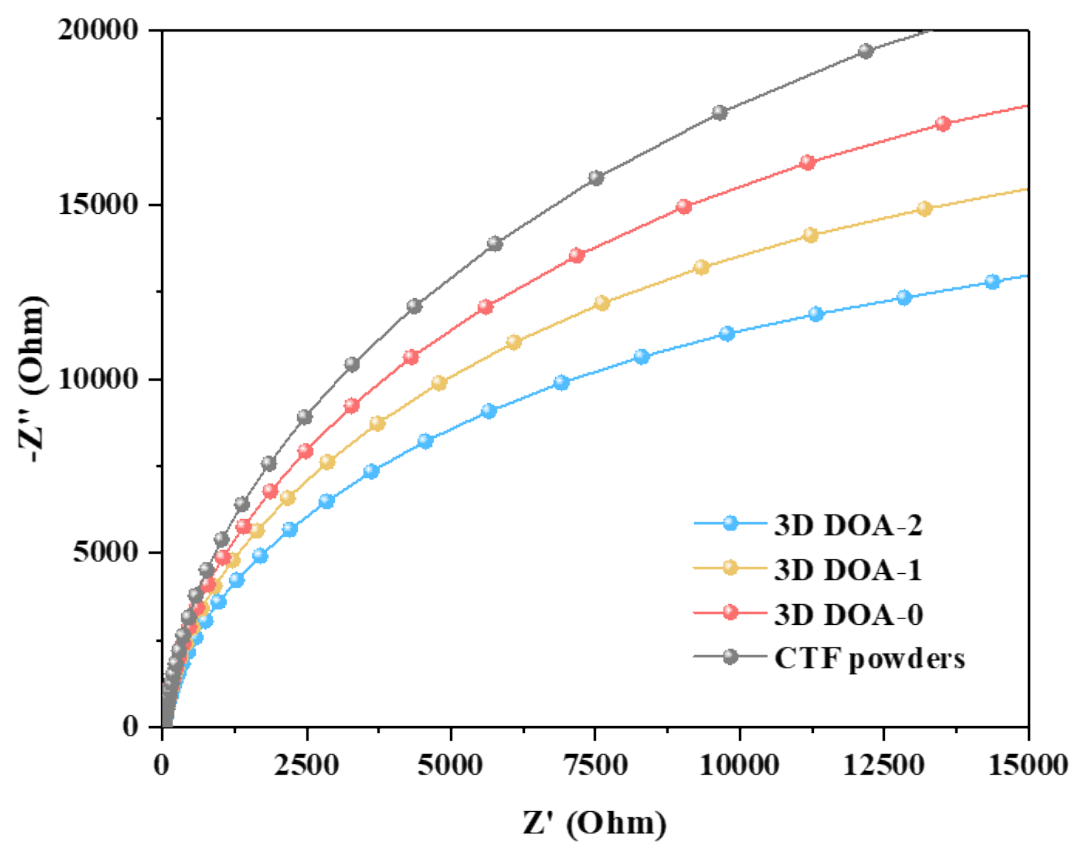

Figure S-11. The charge transfer resistance (RCT) recorded using EIS of 3D DOAs and CTF powders. 


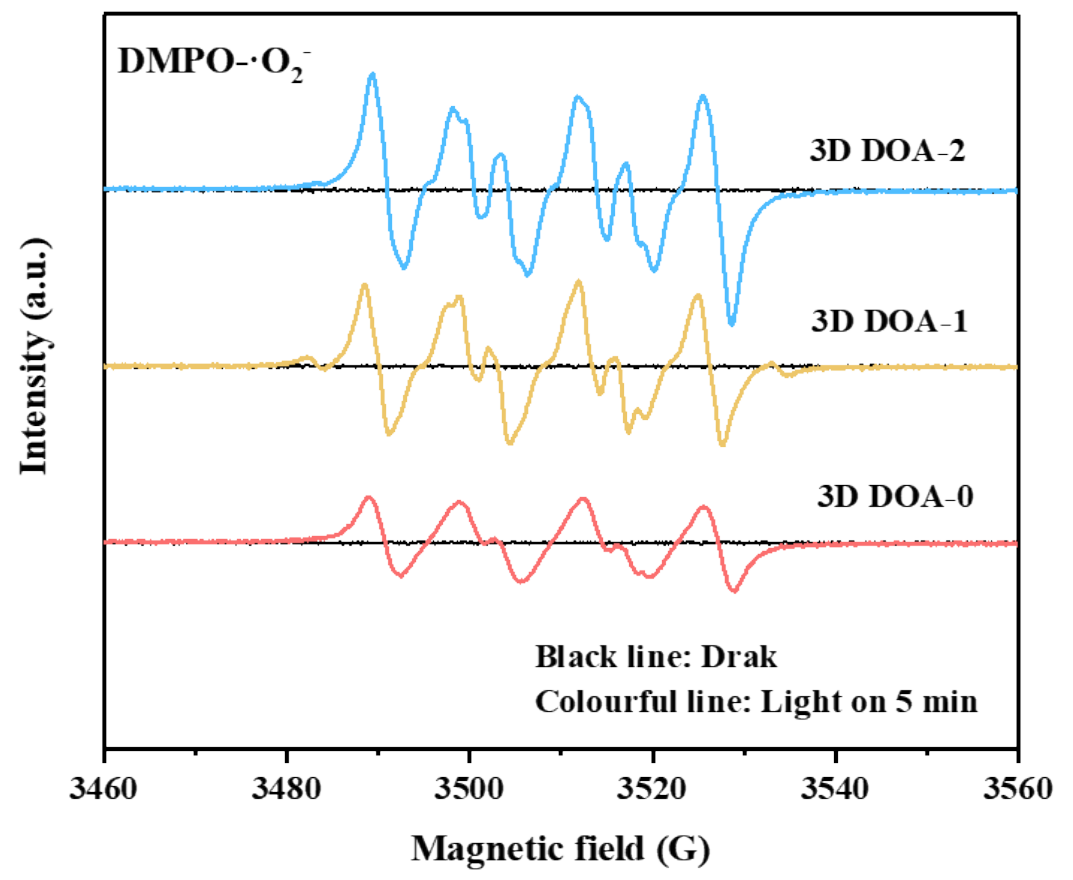

Figure S-12. DMPO spin-trapping ESR spectra recorded for a methanol dispersion of the 3D DOAs for DMPO- $\cdot \mathrm{O}_{2}^{-}$. 


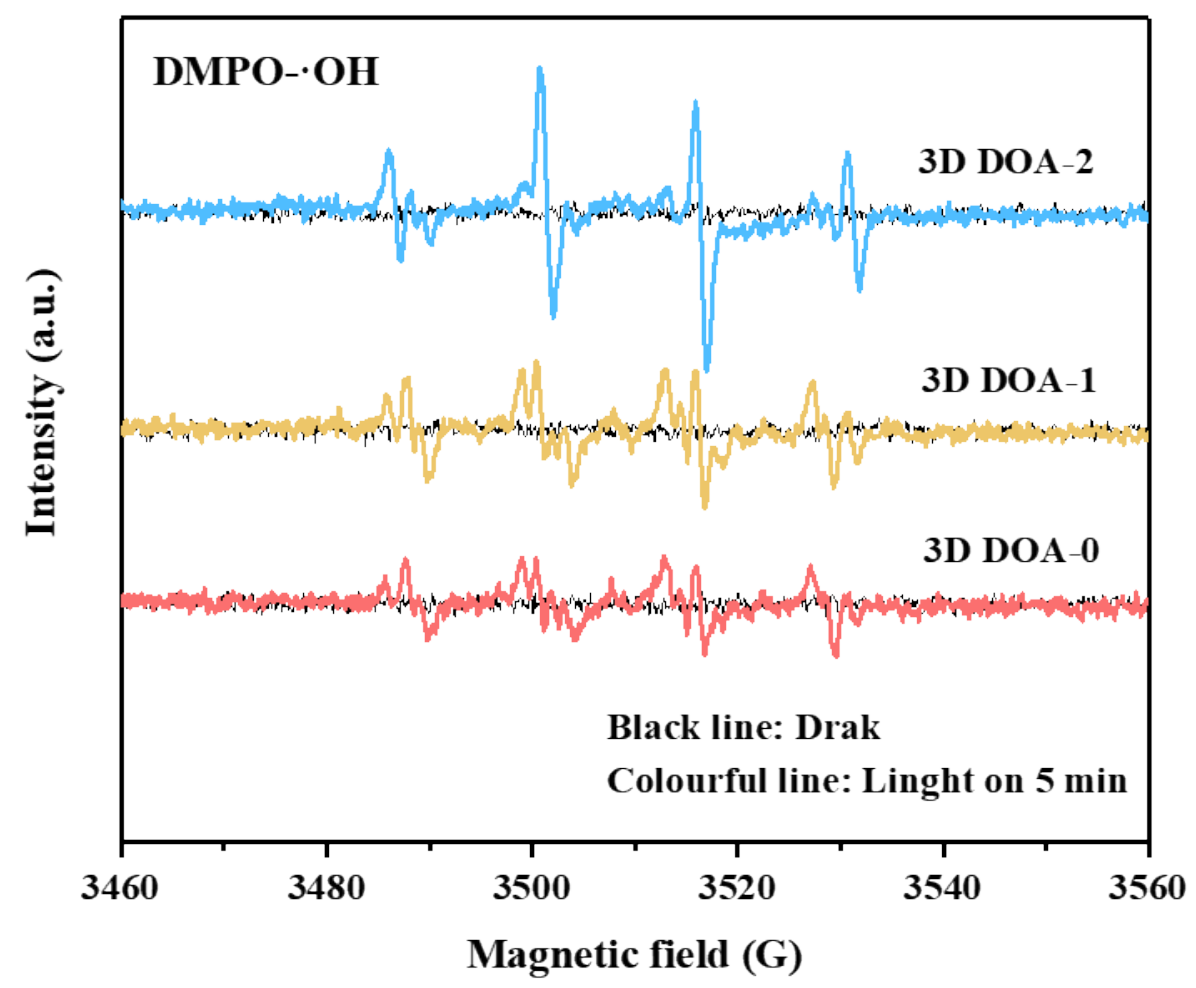

Figure S-13. DMPO spin-trapping ESR spectra recorded for an aqueous dispersion of the $3 \mathrm{D}$ DOAs for DMPO- $\mathrm{OH}$. 


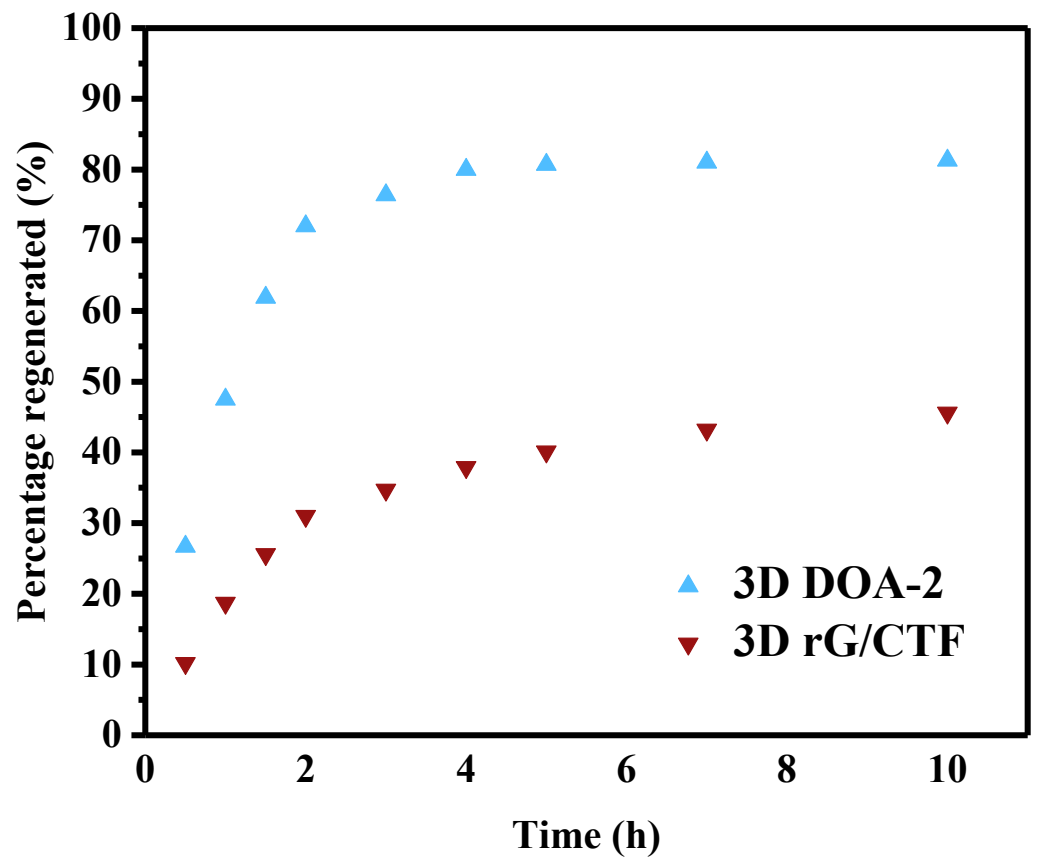

Figure S-14. Comparison of regeneration percentage between 3D DOA-2 and 3D $\mathrm{rG} / \mathrm{CTF}$. 


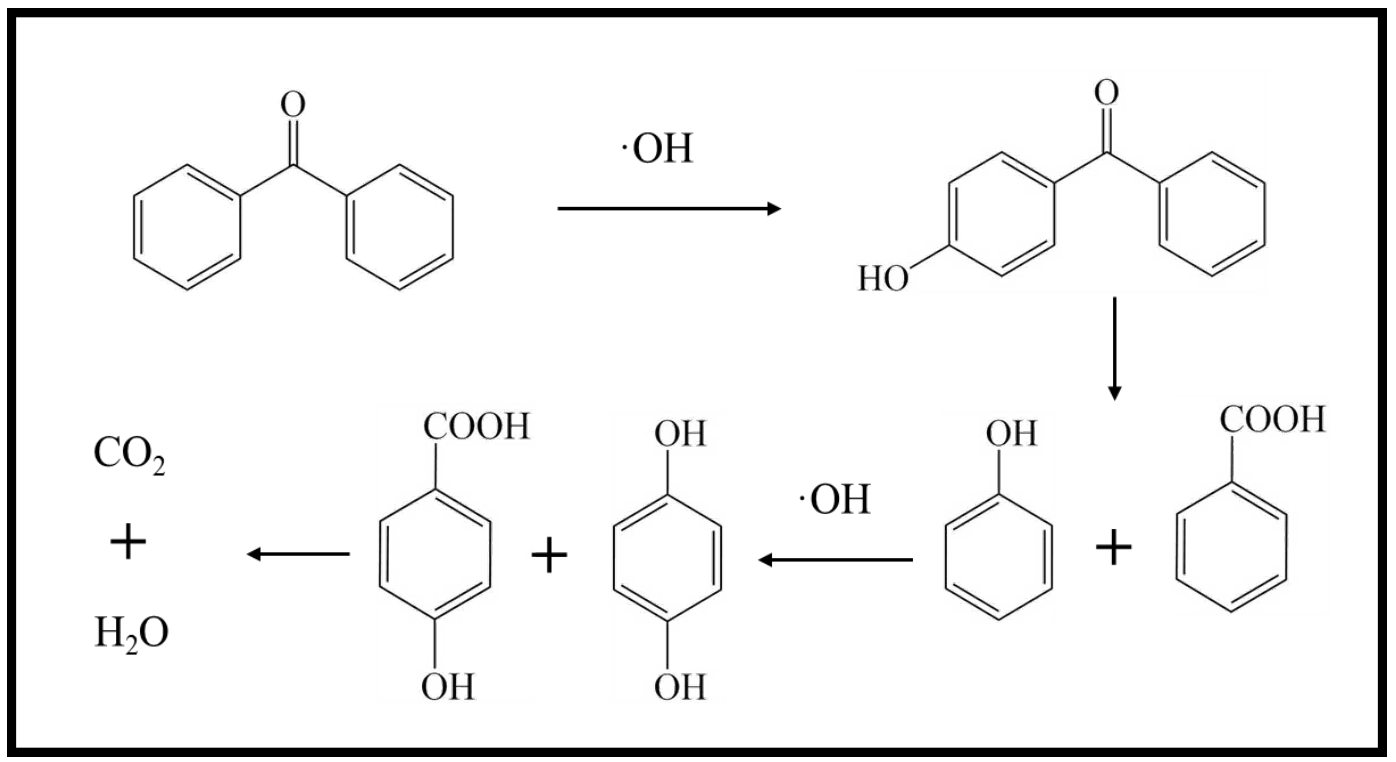

Figure S-15. Intermediates detected by HPLC in the photocatalytic regeneration of 3D DOA-2 adsorbed BP. 


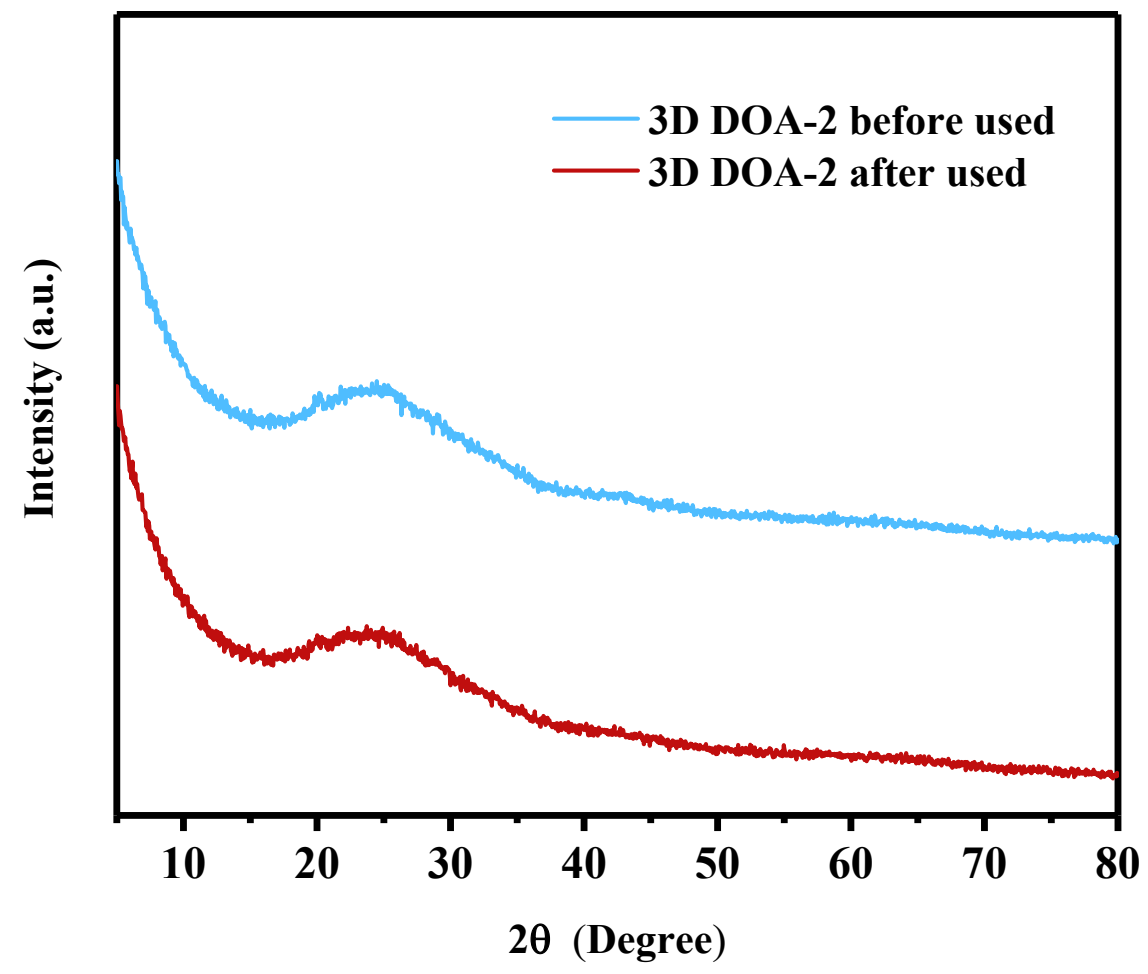

Figure S-16. XRD spectra of 3D DOA-2 before and after used 


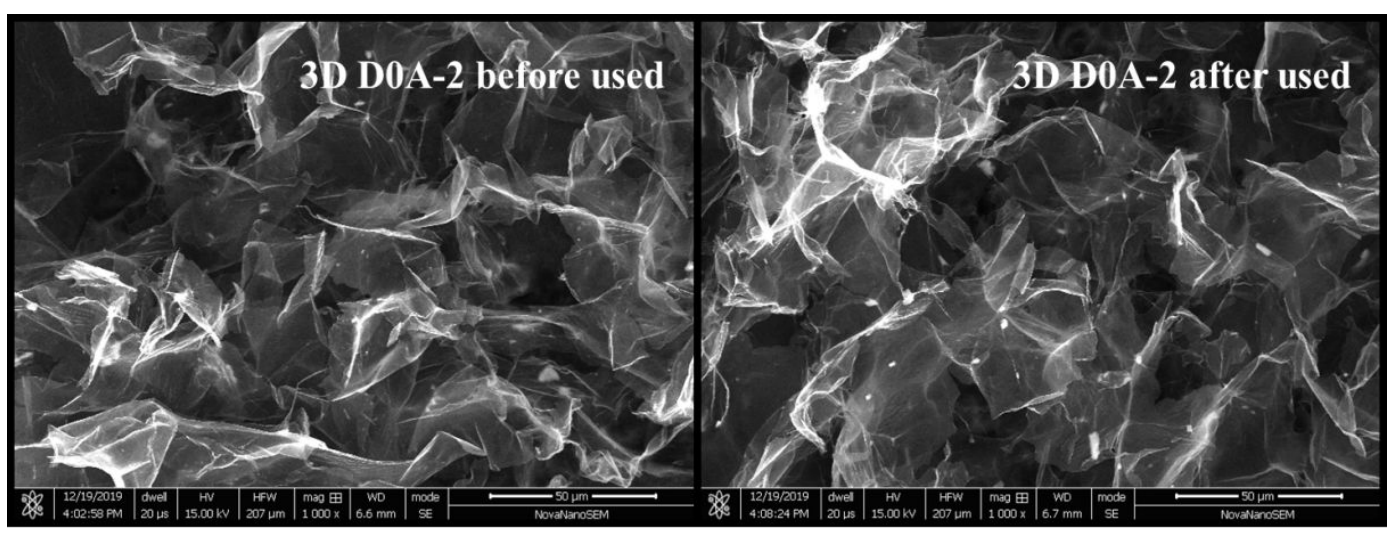

Figure S-17. SEM of 3D DOA-2 before and after used 


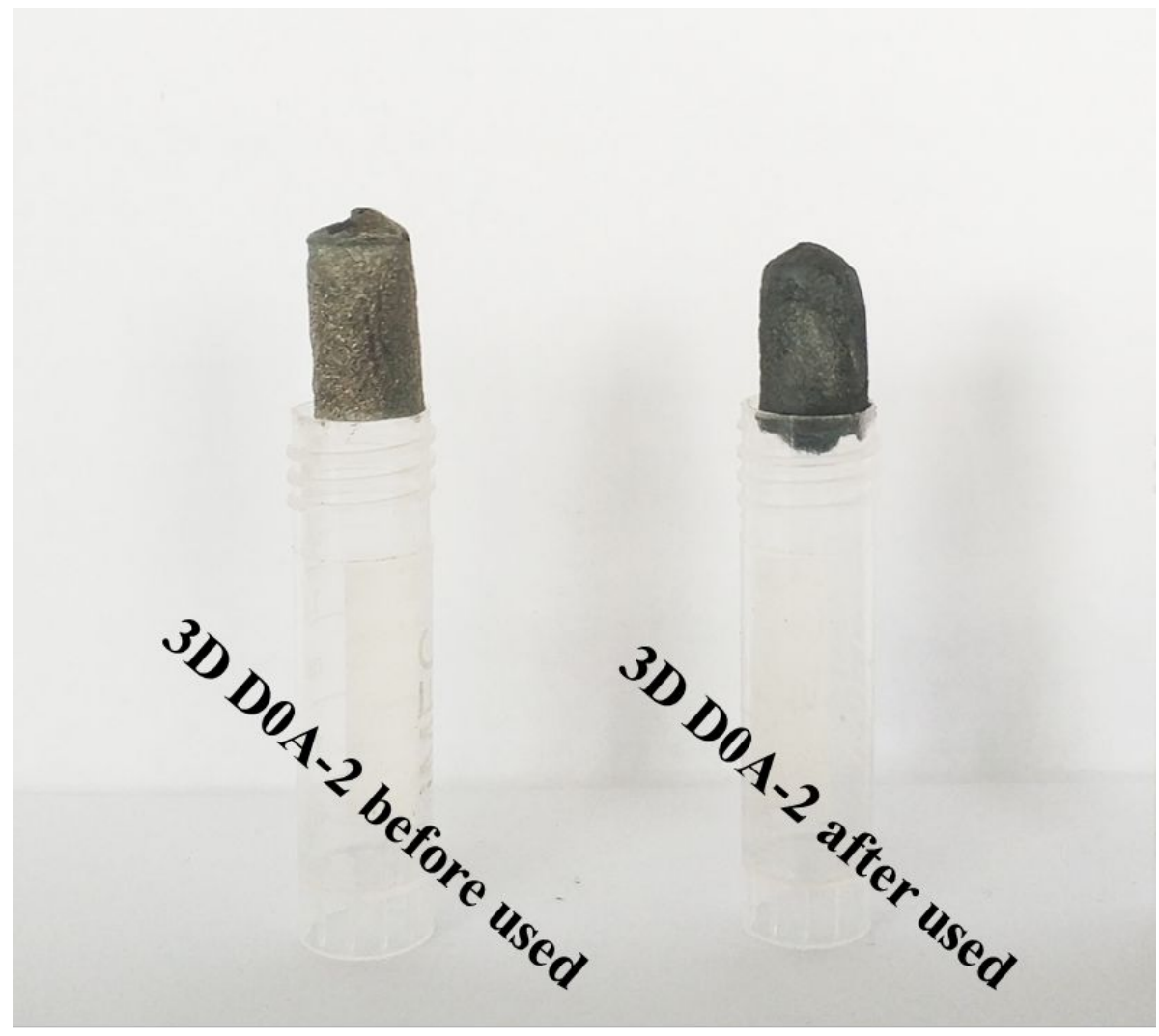

Figure S-18. Optical photo of 3D DOA-2 before and after used 
Table S-1. Physico-chemical characteristics of water from West Lake.

\begin{tabular}{llll}
\hline Cations & Concentration $\left(\mathrm{mg} \mathrm{L}^{-1}\right)$ & Anions & Concentration $\left(\mathbf{m g ~ L}^{-1}\right)$ \\
\hline $\mathrm{Ca}^{2+}$ & 51.21 & $\mathrm{SO}^{2-}$ & 18.78 \\
$\mathrm{Mg}^{2+}$ & 22.58 & $\mathrm{Cl}^{-}$ & 28.64 \\
$\mathrm{Na}^{+}$ & 24.23 & $\mathrm{HCO}_{3}^{-}$ & 52.58 \\
$\mathrm{~K}^{+}$ & 1.96 & $\mathrm{NO}_{3}^{-}$ & 3.7 \\
$\mathrm{NH}^{4+}$ & 0.8 & $\mathrm{NO}_{2}^{-}$ & 0.35 \\
\hline
\end{tabular}


Table S-2. The elemental (C, H, O, N) concentrations of 3D DOA-0, 3D DOA-1 and 3D DOA-2.

\begin{tabular}{llll}
\hline Sample & 3D DOA-0 & 3D DOA-1 & 3D DOA-2 \\
\hline $\mathrm{C} / \%$ & 61.2 & 67.0 & 71.7 \\
$\mathrm{H} / \%$ & 3.03 & 4.85 & 8.59 \\
$\mathrm{O} / \%$ & 26.2 & 15.8 & 5.84 \\
$\mathrm{~N} / \%$ & 9.92 & 12.5 & 14.2 \\
$\mathrm{O} / \mathrm{C}$ & 0.321 & 0.177 & 0.0611 \\
$\mathrm{~N} / \mathrm{C}$ & 0.139 & 0.160 & 0.170 \\
\hline
\end{tabular}


Table S-3. The chemical bonds in 3D DOA-0, 3D DOA-1 and 3D DOA-2 derived from the XPS C 1s and N 1s data.

\begin{tabular}{|c|c|c|c|}
\hline Sample & 3D DOA-0 & 3D DOA-1 & 3D DOA-2 \\
\hline $\mathrm{SP}^{2}(\%)$ & 38.44 & 47.08 & 63.44 \\
\hline $\mathrm{SP}^{3}(\%)$ & 12.43 & 12.93 & 19.13 \\
\hline $\mathrm{C}=\mathrm{N}(\%)$ & 6.43 & 4.27 & 2.79 \\
\hline $\mathrm{C}-\mathrm{O}(\%)$ & 33.25 & 24.82 & 3.11 \\
\hline C-N (\%) & 6.36 & 8.91 & 9.91 \\
\hline $\mathrm{C}=\mathrm{O}(\%)$ & 3.09 & 1.99 & 1.62 \\
\hline $\mathrm{C}-\mathrm{N}=\mathrm{C}(\%)$ & 78.66 & 59.62 & 41.15 \\
\hline C-NH-C (\%) & 21.34 & 40.38 & 58.85 \\
\hline$-\mathrm{OH} /-\mathrm{O}-(\mu \mathrm{mol} / \mathrm{g})$ & 16957 & 13858 & 1858 \\
\hline $\begin{array}{l}\mathrm{C}=\mathrm{O} /-\mathrm{COOH} \\
(\mu \mathrm{mol} / \mathrm{g})\end{array}$ & 1576 & 1111 & 968 \\
\hline $\begin{array}{l}\text { Triazine nitrogen } \\
(\mu \mathrm{mol} / \mathrm{g})\end{array}$ & 5574 & 5323 & 4174 \\
\hline $\begin{array}{l}\text { Pyrrole nitrogen } \\
(\mu \mathrm{mol} / \mathrm{g})\end{array}$ & 1512 & 3605 & 5969 \\
\hline
\end{tabular}


Table S-4. Adsorption kinetic parameters obtained for BP, 4-HBP and BP-2 on 3D DOA-0, 3D DOA-1 and 3D DOA-2.*

\begin{tabular}{|c|c|c|c|c|c|c|c|}
\hline \multirow{2}{*}{ Pollutant } & \multirow{2}{*}{ Adsorbent } & \multicolumn{3}{|c|}{ Pseudo first-order } & \multicolumn{3}{|c|}{ Pseudo second-order } \\
\hline & & $q_{\mathrm{e}}(\mu \mathrm{mol} / \mathrm{g})$ & $k_{1}(1 / \mathbf{s})$ & $\mathbf{R}^{2}$ & $q_{\mathrm{e}}(\mu \mathrm{mol} / \mathrm{g})$ & $k_{2}(\mathrm{~g} /(\mu \mathrm{mol} \cdot \mathrm{s}))$ & $\mathbf{R}^{2}$ \\
\hline \multirow[t]{3}{*}{ BP } & 3D DOA-0 & 578 & 0.0222 & 0.984 & 632 & 0.0302 & 0.938 \\
\hline & 3D DOA-1 & 740 & 0.0187 & 0.997 & 811 & 0.0259 & 0.976 \\
\hline & 3D DOA-2 & 907 & 0.0169 & 0.985 & 991 & 0.0243 & 0.979 \\
\hline \multirow[t]{3}{*}{ 4-HBP } & 3D DOA-0 & 568 & 0.0137 & 0.979 & 624 & 0.0194 & 0.970 \\
\hline & 3D DOA-1 & 622 & 0.0305 & 0.984 & 671 & 0.0442 & 0.963 \\
\hline & 3D DOA-2 & 890 & 0.0240 & 0.990 & 964 & 0.0347 & 0.953 \\
\hline \multirow[t]{3}{*}{ BP-2 } & 3D DOA-0 & 260 & 0.0168 & 0.986 & 288 & 0.0221 & 0.939 \\
\hline & 3D DOA-1 & 308 & 0.0156 & 0.993 & 339 & 0.0212 & 0.954 \\
\hline & 3D DOA-2 & 711 & 0.0328 & 0.985 & 764 & 0.0486 & 0.965 \\
\hline
\end{tabular}

* The solid solution ratio was $1 \mathrm{mg} / 50 \mathrm{~mL}$. The initial concentrations of BP, 4-HBP and BP-2 were $20 \mu \mathrm{mol} / \mathrm{L}$. 
Table S-5. Regression parameters obtained for the adsorption isotherms of BP, 4-HBP and BP-2 on 3D DOA-0, 3D DOA-1 and 3D DOA-2 fitted using the Freundlich and Langmuir models.

\begin{tabular}{|c|c|c|c|c|c|c|c|}
\hline \multirow{2}{*}{ Pollutant } & \multirow{2}{*}{ Adsorbent } & \multicolumn{3}{|c|}{ Freundlich model } & \multicolumn{3}{|c|}{ Langmuir model } \\
\hline & & $K_{\mathrm{f}}\left((\mu \mathrm{mol} / \mathrm{g}) /(\mu \mathrm{mol} / \mathrm{L})^{1 / n}\right)$ & $N$ & $\mathbf{R}^{2}$ & $q_{\mathrm{m}}(\mu \mathrm{mol} / \mathrm{g})$ & $K_{\mathrm{L}}(\mathrm{L} / \mathrm{g})$ & $\mathbf{R}^{2}$ \\
\hline $\mathrm{BP}$ & 3D DOA-1 & 700 & 0.210 & 0.707 & 1887 & 0.300 & 0.914 \\
\hline \multirow[t]{3}{*}{ 4-HBP } & 3D DOA-0 & 406 & 0.257 & 0.728 & 1477 & 0.120 & 0.930 \\
\hline & 3D DOA-1 & 457 & 0.266 & 0.721 & 1731 & 0.121 & 0.917 \\
\hline & 3D DOA-2 & 868 & 0.202 & 0.738 & 2209 & 0.444 & 0.957 \\
\hline BP-2 & 3D DOA-2 & 538 & 0.266 & 0.830 & 1957 & 0.145 & 0.978 \\
\hline
\end{tabular}


Table S-6. Regression parameters obtained for the adsorption isotherms of BP on 3D GO, 3D rGO and 3D rG fitted using the Freundlich and Langmuir models.

\begin{tabular}{|c|c|c|c|c|c|c|c|}
\hline \multirow{2}{*}{ Pollutant } & \multirow{2}{*}{ Adsorbent } & \multicolumn{3}{|c|}{ Freundlich model } & \multicolumn{3}{|c|}{ Langmuir model } \\
\hline & & $K_{\mathrm{f}}\left((\mu \mathrm{mol} / \mathrm{g}) /(\mu \mathrm{mol} / \mathrm{L})^{1 / n}\right)$ & $N$ & $\mathbf{R}^{2}$ & $q_{\mathrm{m}}(\mu \mathrm{mol} / \mathrm{g})$ & $K_{\mathrm{L}}(\mathrm{L} / \mathrm{g})$ & $\mathbf{R}^{2}$ \\
\hline $\mathrm{BP}$ & $3 \mathrm{D} \mathrm{rGO}$ & 740 & 0.209 & 0.714 & 1935 & 0.317 & 0.912 \\
\hline
\end{tabular}


Table S-7. The percentage of the adsorption capacity regenerated for 3D DOA-0, 3D DOA-1, 3D DOA-2 and 3D rG/CTF during the photocatalytic regeneration process.

\begin{tabular}{|c|c|c|c|c|c|c|c|c|c|c|}
\hline \multirow{2}{*}{ Pollutant } & \multirow{2}{*}{ Adsorbent } & \multicolumn{9}{|c|}{ Regeneration (\%) } \\
\hline & & $0.5 \mathrm{~h}$ & $1 \mathrm{~h}$ & $1.5 \mathrm{~h}$ & $2 \mathrm{~h}$ & $3 \mathrm{~h}$ & $4 \mathrm{~h}$ & $5 \mathrm{~h}$ & $7 \mathrm{~h}$ & $10 \mathrm{~h}$ \\
\hline \multirow[t]{4}{*}{ BP } & 3D DOA-0 & 12.3 & 22.3 & 43.2 & 53.2 & 67.3 & 69.0 & 69.8 & 70.6 & 70.6 \\
\hline & 3D DOA-1 & 19.7 & 38.9 & 53.8 & 64.8 & 71.7 & 75.6 & 76.3 & 76.6 & 76.7 \\
\hline & 3D DOA-2 & 26.7 & 47.5 & 61.9 & 72.0 & 76.4 & 80.0 & 80.7 & 81.0 & 81.3 \\
\hline & 3D rG/CTF & 10.2 & 18.7 & 25.6 & 31.0 & 34.7 & 37.9 & 40.1 & 43.2 & 45.6 \\
\hline \multirow[t]{3}{*}{ 4-HBP } & 3D DOA-0 & 16.1 & 35.0 & 47.7 & 58.9 & 66.0 & 72.9 & 74.3 & 75.4 & 75.9 \\
\hline & 3D DOA-1 & 24.2 & 39.2 & 53.3 & 67.0 & 77.0 & 81.6 & 82.1 & 82.5 & 82.9 \\
\hline & 3D DOA-2 & 25.6 & 43.2 & 57.2 & 68.4 & 80.3 & 83.9 & 85.0 & 85.6 & 85.7 \\
\hline \multirow[t]{3}{*}{ BP-2 } & 3D DOA-0 & 16.6 & 30.4 & 42.2 & 55.6 & 68.7 & 79.4 & 79.7 & 80.1 & 80.2 \\
\hline & 3D DOA-1 & 23.1 & 39.6 & 50.9 & 64.2 & 75.2 & 83.4 & 85.1 & 85.4 & 85.9 \\
\hline & 3D DOA-2 & 28.4 & 45.6 & 64.0 & 74.5 & 86.1 & 91.0 & 91.8 & 92.0 & 92.3 \\
\hline
\end{tabular}


Table S-8. The percentage of the adsorption capacity regenerated for 3D DOA-0, 3D DOA-1 and 3D DOA-2 in the $2^{\text {nd }}, 3^{\text {rd }}$ and $4^{\text {th }}$ cycle of the photocatalytic regeneration process.

\begin{tabular}{|c|c|c|c|c|}
\hline \multirow{2}{*}{ Pollutant } & \multirow{2}{*}{ Adsorbent } & \multicolumn{3}{|c|}{ Regeneration (\%) } \\
\hline & & $2^{\text {nd }}$ & $3^{\text {rd }}$ & $4^{\text {th }}$ \\
\hline \multirow[t]{3}{*}{$\mathrm{BP}$} & 3D DOA-0 & 70.6 & 69.0 & 67.3 \\
\hline & 3D DOA-1 & 76.7 & 74.8 & 73.8 \\
\hline & 3D DOA-2 & 81.3 & 79.7 & 77.5 \\
\hline \multirow[t]{3}{*}{ 4-HBP } & 3D DOA-0 & 75.9 & 72.8 & 72.0 \\
\hline & 3D DOA-1 & 82.9 & 80.8 & 79.7 \\
\hline & 3D DOA-2 & 85.7 & 83.6 & 81.9 \\
\hline \multirow[t]{3}{*}{ BP-2 } & 3D DOA-0 & 80.2 & 78.8 & 77.2 \\
\hline & 3D DOA-1 & 85.9 & 82.9 & 81.5 \\
\hline & 3D DOA-2 & 92.3 & 90.2 & 88.7 \\
\hline
\end{tabular}


Table S-9. The percentage removal of BP and percentage of the adsorption capacity regenerated for 3D DOA-0, 3D DOA-1 and 3D DOA-2 over 7 days (7 night-day cycles).

\begin{tabular}{lllllllll}
\hline \multirow{2}{*}{} & Adsorbent & 1D & 2D & 3D & 4D & 5D & 6D & 7D \\
\hline \multirow{2}{*}{ 3D DOA-0 } & Removal (\%) & 66.5 & 60.9 & 52.2 & 45.1 & 42.3 & 39.3 & 38.5 \\
& Regeneration (\%) & & 91.5 & 78.6 & 67.8 & 63.6 & 59.1 & 57.9 \\
& Removal (\%) & 86.1 & 81.3 & 72.6 & 66.3 & 63.2 & 60.9 & 59.5 \\
& & & & & & & & \\
3D DOA-1 & Regeneration (\%) & & 94.4 & 84.4 & 77.1 & 73.4 & 70.7 & 69.2 \\
& Removal (\%) & 100 & 94.5 & 88.7 & 83.6 & 81.3 & 79.8 & 77.4 \\
& & & & & & & & \\
3D DOA-2 & Regeneration (\%) & & 94.5 & 88.7 & 83.6 & 81.3 & 79.8 & 77.4 \\
\hline
\end{tabular}


Table S-10. Changes in TOC concentration before and after BP removal by 3D DOA-0, 3D DOA-1 and 3D DOA-2 over 7 days (7 night-day cycles).

\begin{tabular}{ccc}
\hline \multirow{2}{*}{ Adsorbent } & \multicolumn{2}{c}{ TOC Concentration $\left(\mathbf{m g ~ L}^{-1}\right)$} \\
\cline { 2 - 3 } & Before treatment & After treatment \\
\hline 3D DOA-0 & 9.7 & 5.3 \\
3D DOA-1 & 9.7 & 5.7 \\
3D DOA-2 & 9.7 & 5.2 \\
\hline
\end{tabular}

